\title{
Pengaruh Iklim Organisasi terhadap Kinerja Guru PAUD di Kota Depok
}

\author{
Raudhatul Janah', Zarina Akbar², Elindra Yetti ${ }^{3}$ \\ Pendidikan Anak Usia Dini, Universitas Negeri Jakarta \\ DOI: $10.31004 /$ obsesi.v4i1.236
}

\begin{abstract}
Abstrak
Tujuan penelitian ini dilakukan untuk mengetahui seberapa besar kinerja guru Pendidikan Anak Usia Dini di Kota Depok. Penelitian ini menggunakan metode kuantitatif asosiatif dengan jenis penelitian kausal dan menggunakan teknik analisis jalur (path analysis). Penelitian ini melibatkan 102 guru Pendidikan Anak Usia Dini di Kelurahan Gandul, Kecamatan Cinere Kota Depok dengan menggunakan teknik cluster random sampling. Penelitian ini menggunakan instrumen survei dan menganalisisnya menggunakan program Analysis of Moment Structural 21 (AMOS 21). Hasil dari penelitian ini menyimpulkan bahwa terdapat pengaruh langsung positif iklim organisasi terhadap kinerja guru PAUD di Kota Depok dengan nilai koefisien korelasi sebesar 0.612 dan nilai koefisien jalur sebesar 0.442 .
\end{abstract}

Kata Kunci: iklim organisasi; kinerja guru; pendidikan anak usia dini

\begin{abstract}
The purpose of this study was conducted to discover the effects of organization climate and job satisfaction on the kindergarten teacher performances in Depok City. This study using associative quantitative method with causal research and path analysis techniques. This study involved 102 respondents using cluster random sampling technique. The respondents are kindergarten teachers in Kelurahan Gandul, Kecamatan Cinere, Depok City. This research uses survey instruments and analyzes them using the Analysis of Moment Structural 21 (AMOS 21) program. The results of this study concluded that there was a positive direct effect on organizational climate to kindergarten teacher performance in Depok City $(r=0.612)$ and $(\beta=0.442)$.
\end{abstract}

Keywords: organizational climate; teacher performance; kindergarten

Copyright (c) 2019 Raudhatul Janah, Zarina Akbar, Elindra Yetti

$\triangle$ Corresponding author:

Email Address : rara1889@yahoo.com (Jakarta, Indonesia)

Received 17 July 2019, Accepted 9 October 2019, Published 7 November 2019

\section{PENDAHULUAN}

Guru merupakan salah satu komponen yang mempunyai peran utama dalam usaha meningkatkan mutu pendidikan. Pendidikan sangat diperlukan untuk mewujudkan cita-cita kemerdekaan bangsa Indonesia dan hal ini merupakan salah satu cita-cita nasional, yaitu mencerdaskan kehidupan bangsa. Tanpa guru, maka aktivitas di sekolah tidak dapat berjalan dengan baik. Selain itu, peran guru sangat penting kedudukannya sebagai pemberi 
pembelajaran kepada siswa sebagai generasi bangsa karena guru langsung bersinggungan dengan peserta didik. Untuk mewujudkannya diperlukan tenaga pendidik yang berkinerja tinggi, yaitu guru yang berkualitas dan bertanggung jawab bagi lembaga pendidikan (Wardani, 2014).

Guru dengan kinerja tinggi akan berusaha menunjukkan prestasi yang lebih tinggi guna meningkatkan kualitas mengajarnya sehingga mutu pembelajaran semakin meningkat. Kinerja guru akan terlihat dari bagaimana guru tersebut melaksanakan tugas pokoknya. Seorang guru dituntut untuk mampu menyusun perencanaan pembelajaran yang baik karena dengan perencanaan yang baik maka guru dapat melaksanakan pembelajaran sesuai dengan tujuan yang diharapkan. (Nugraeni, 2016)

Kinerja guru merupakan salah satu penentu tinggi rendahnya mutu pendidikan. Pendidikan dapat dinyatakan bermutu tinggi apabila guru bekerja secara professional. Guru professional adalah guru yang memiliki kemampuan dan kehalian khusus dalam bidang keguruan sehingga ia mampu melakukan tugas dan fungsinya terhadap perencanaan pembelajaran, pelaksanaan pembelajaran, pengelolaan kurikulum, pelayanan siswa, hubungan sekolah terhadap masyarakat, pengelolaan iklim sekolah, dan evaluasi program sekolah. (Jakaria, 2014)

Kinerja guru merupakan hasil yang dicapai oleh guru dalam melaksanakan tugastugas yang dibebankan kepadanya yang didasarkan atas kecakapan, pengalaman, kesungguhan, dan penggunaan waktu. Kinerja guru akan baik jika guru telah melaksanakan unsur-unsur yang terdiri atas kesetiaan dan komitmen yang tinggi pada tugas mengajar, menguasai dan mengembangkan bahan pelajaran, kedisiplinan dalam mengajar, kreativitas dalam pelaksanaan pengajaran, kerjasama dengan semua warga di sekolah, kepemimpinan yang menjadi panutan siswa, serta tanggung jawab terhadap tugasnya (Wahyudi, 2012).

Oleh sebab itu, menyadari pentingnya kinerja guru dalam melaksanakan tugasnya maka diperlukan beberapa faktor yang memengaruhi, salah satunya adalah iklim organisasi yang kondusif, dimana akan memberikan peluang dan menumbuhkan kreativitas serta inovasi dari para guru, yaitu berinovasi lebih bebas untuk mencari cara-cara baru dalam menyelesaikan suatu pekerjaan. Iklim organisasi harus diperhatikan sebagai salah satu indikator dalam peningkatan kualitas guru. Iklim organisasi atau iklim sekolah tempat guru melaksanakan tugas meliputi lingkungan fisik, sosial, dan akademik. Kondisi lingkungan ini akan memengaruhi perilaku warga sekolah dalam melaksanakan tugas dan tanggung jawabnya.

Dengan demikian, iklim organisasi merupakan salah satu faktor yang dapat memengaruhi kinerja dari seorang guru. Hal ini sesuai dengan teori yang dijelaskan oleh Snell dan Bohlander (2010) bahwa "organizational climate can affect a person's performance" (iklim organisasi dapat memengaruhi kinerja seseorang). Oleh sebab itu, iklim organisasi disebuah lembaga dalam konteks penelitian ini adalah sekolah harus memiliki iklim yang kondusif agar pegawai atau guru dapat bekerja sesuai dengan tuntutan pekerjaannya. Dengan demikian, kinerja seseorang dipengaruhi oleh iklim organisasi yang kondusif.

Gareth R \& George, (2012) menjelaskan juga bahwa iklim organisasi merupakan kekuatan yang memengaruhi baik secara langsung maupun tidak langsung terhadap kinerja seseorang. Oleh sebab itu, iklim organisasi harus diperhatikan sebagai salah satu indikator dalam peningkatan kualitas guru. Kemudian Davis dan Newstrom juga menjelaskan bahwa iklim organisasi dapat memengaruhi kinerja. Ini dapat dikatakan bahwa iklim merupakan konsep sistem yang mencerminkan keseluruhan gaya hidup suatu organisasi. (Keith \& Newstrom, 2009) Apabila gaya hidup ini dapat ditingkatkan, kemungkinan besar tercapai peningkatan kinerja yang dapat diukur.

Saat ini, kinerja guru PAUD menjadi isu yang sering dibicarakan oleh kalangan pendidikan. Iriana Joko Widodo mengatakan bahwa Kementerian Pendidikan dan Kebudayaan diwajibkan untuk memberikan perhatian yang lebih besar kepada guru-guru PAUD dimana kualitas guru-guru PAUD harus ditingkatkan terutama guru-guru PAUD 
yang berada di daerah karena peran guru PAUD sangat penting dalam membentuk generasi bangsa yang cerdas sejak usia dini (Oebaidillah, 2016). Lebih jelas lagi, guru PAUD merupakan gerbang utama yang mengantarkan anak usia dini untuk mencapai tingkat perkembangan yang optimal. Dalam hal ini, dibutuhkan pengetahuan yang cukup agar mampu melayani dan membentuk anak menjadi generasi emas di masa yang akan datang.

Berdasarkan hasil observasi yang dilakukan peneliti, muncul data yang dapat diidentifikasi sebagai masalah, yaitu sebagian sekolah PAUD di Kota Depok masih mempunyai iklim organisasi yang kurang kondusif karena banyak sekolah PAUD yang terletak di pinggir jalan raya sehingga terdengar bising saat melakukan pembelajaran dan kinerja dari sebagian guru PAUD di Kota Depok masih kurang memuaskan karena banyak ditemukan guru yang sering tidak masuk, guru yang menggunakan metode dan media yang kurang variatif, serta guru yang tidak membuat rancangan pelaksanaan pembelajaran.

Dari yang sudah dipaparkan peneliti di atas tentang kinerja guru PAUD berdasarkan fakta yang ada bahwa kinerja guru PAUD khususnya di Kota Depok masih rendah, sehingga diperlukan pengaruh terhadap kinerja guru PAUD salah satunya dengan menciptakan iklim organisasi yang kondusif. Lebih lanjut lagi, di Kota Depok belum ada yang meneliti tentang kinerja guru PAUD sehingga berdasarkan latar belakang dan identifikasi masalah tersebut, maka rumusan masalah dari penelitian ini adalah apakah terdapat pengaruh langsung iklim organisasi terhadap kinerja guru PAUD di Kota Depok.

\section{METODOLOGI}

Penelitian ini menggunakan pendekatan kuantitatif dengan metode penelitian kausal analisis jalur (path analysis). Teknik analisis jalur digunakan untuk menguji kesesuaian model, hubungan antar variabel, kemudian dilanjutkan pengujian pengaruh langsung dari tiap-tiap variabel eksogen, yaitu iklim organisasi terhadap variabel endogen, yaitu kinerja. Populasi pada penelitian ini adalah guru PAUD yang ada di wilayah kota Depok. Sedangkan sampel penelitiannya dengan menggunakan teknik kluster sampling atau mengambil wakil dari setiap wilayah geografis yang ada (Riduwan dan Kuncoro, 2013). Pengukuran terhadap iklim organisasi dalam penelitian ini dilakukan dengan menggunakan kuesioner berdasarkan definisi operasional mengenai iklim organisasi, maka dapat dibuat kisi-kisi instrumen sebanyak 27 butir dan serangkaian pernyataan tersebut menggunakan skala likert, yaitu Sangat Sesuai (SS), Sesuai (S), Cukup Sesuai (CS), Kurang Sesuai (KS), Tidak Sesuai (TS). Skor atas jawaban berupa pertanyaan positif adalah pilihan Sangat Sesuai $(\mathrm{SS})=5$, Sesuai $(\mathrm{S})=4$, Cukup Sesuai $(\mathrm{CS})=3$, Kurang Sesuai $(\mathrm{KS})=2$, Tidak Sesuai $(\mathrm{TS})=1$. Skor ini dimaksudkan untuk memberikan informasi mengenai butir-butir yang digunakan untuk uji keabsahan butir.

Sedangkan pengukuran terhadap kinerja dalam penelitian ini dilakukan dengan menggunakan kuesioner berdasarkan definisi operasional mengenai kinerja, maka dapat dibuat kisi-kisi instrumen sebanyak 22 butir dan serangkaian pernyataan tersebut menggunakan skala likert, yaitu Selalu (S), Sering (SR), Jarang (JR), Pernah (P), Tidak Pernah (TP). Skor atas jawaban berupa pertanyaan positif adalah pilihan Selalu $(\mathrm{S})=5$, Sering $(\mathrm{SR})=$ 4 , Jarang $(J R)=3$, Pernah $(\mathrm{P})=2$, Tidak Pernah $(\mathrm{TP})=1$. Sedangkan skor atas jawaban berupa pertanyaan negatif adalah pilihan Selalu $(S)=1$, Sering $(S R)=2$, Jarang $(J R)=3$, Pernah $(\mathrm{P})=4$, Tidak Pernah $(\mathrm{TP})=5$ Skor ini dimaksudkan untuk memberikan informasi mengenai butir-butir yang digunakan untuk uji keabsahan butir.

\section{HASIL DAN PEMBAHASAN}

Pengambilan data penelitian dilakukan dalam empat bulan, yakni pada bulan November 2017 sampai Februari 2018 di PAUD Kelurahan Gandul Kecamatan Cinere Kota Depok. Peneliti terlebih dahulu mengajukan surat ijin penelitian kepada kepala sekolah untuk mengambil data penelitian. Selang beberapa hari peneliti di perbolehkan untuk mengambil data dengan membagikan kuesioner kepada 102 guru di 14 sekolah yang 
berbeda yang berada di PAUD kelurahan Gandul. Data yang telah terkumpul kemudian diolah secara statistik menggunakan program Analysis of Moment Structural 21 (AMOS 21).

Berdasarkan hasil penghitungan analisis jalur, pengaruh langsung iklim organisasi terhadap kinerja, nilai koefisien jalur sebesar 0.442 dan nilai t-hitung sebesar 5.467. Nilai ttabel untuk $a=0,05$ sebesar 1.98 . Oleh sebab itu, nilai t-hitung lebih besar dari pada nilai $t-$ tabel maka Ho ditolak dan $\mathrm{H}_{1}$ diterima. Dengan demikian, dapat disimpulkan bahwa kinerja dipengaruhi secara langsung positif oleh iklim organisasi. Meningkatnya iklim organisasi mengakibatkan peningkatan kinerja.

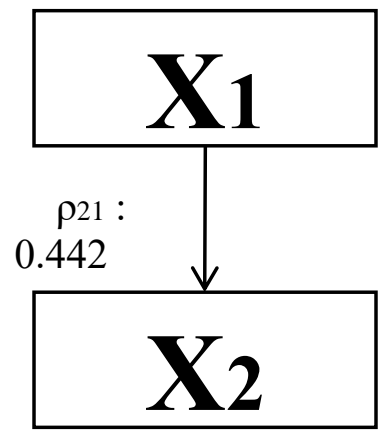

Gambar 1 Diagram Jalur

Tabel 1

Koefisien Jalur Pengaruh $X_{1}$ terhadap $X_{2}$

\begin{tabular}{|c|c|c|c|c|}
\hline \multirow{2}{*}{$\begin{array}{l}\text { Pengaruh } \\
\text { Langsung }\end{array}$} & \multirow{2}{*}{$\begin{array}{l}\text { Koefisien } \\
\text { Jalur }\end{array}$} & \multirow[t]{2}{*}{ t-hitung } & \multicolumn{2}{|l|}{ t-tabel } \\
\hline & & & $\alpha=0,05$ & $a=0,01$ \\
\hline $\mathrm{X}_{1}$ terhadap $\mathrm{X}_{2}$ & 0.442 & $5.467^{* *}$ & 1.98 & 2.63 \\
\hline
\end{tabular}

Hasil penelitian ini senada dengan pendapat beberapa ahli, yaitu menurut Mullins, (2013) mengidentifikasi bahwa pengaruh iklim organisasi terhadap kinerja adalah "organizational climate will influence attitudes which members of the organization bring to bear on their work performance" (iklim organisasi akan memengaruhi sikap anggota organisasi yang akan melahirkan kinerja). Oleh sebab itu, iklim organisasi atau dalam konteks penelitian ini adalah iklim sekolah akan memengaruhi kinerja seseorang, yaitu guru PAUD di dalam sebuah organisasi.

Dengan adanya iklim organisasi yang memiliki suasana menyenangkan, penuh kedamaian, tidak adanya konflik, dan hubungan antar personel berjalan dengan baik, maka seseorang akan merasakan adanya dukungan positif dari organisasi dalam melakukan pekerjaannya, sehingga dapat memengaruhi kinerjanya. Dengan kata lain, iklim organisasi akan mendorong peningkatan kinerja (Wirawan, 2009).

Jones et al. (2011) menjelaskan bahwa iklim organisasi merupakan kekuatan yang memengaruhi baik secara langsung maupun tidak langsung terhadap kinerja seseorang. Oleh sebab itu, iklim organisasi harus diperhatikan sebagai salah satu indikator dalam peningkatan kualitas guru. Selain itu, terdapat penelitian yang menggambarkan adanya pengaruh langsung antara iklim organisasi terhadap kinerja, seperti penelitian yang dilakukan oleh Asi, (2013) yang berjudul Pengaruh Iklim Organisasi dan Burnout terhadap Kinerja Perawat RSUD dr. Doris Sylvanus Palangka Raya berpendapat bahwa iklim organisasi mempunyai pengaruh yang langsung terhadap kinerja dengan nilai koefisien jalur sebesar 0.127. Penelitian tersebut sesuai dengan apa yang dijelaskan oleh Mullins, (2013) bahwa iklim organisasi berpengaruh langsung terhadap sikap kerja dan menentukan kinerja pegawai. Lebih lanjut lagi, menurut Idrus (2006) salah satu faktor iklim organisasi adalah memberikan penghargaan (reward) kepada pegawai berdasarkan kinerja pegawai. 
Dimana menurut Triatna (2015) kinerja dapat diartikan sebagai prestasi, hasil atau kemampuan yang dicapai atau diperlihatkan dari suatu pelaksanaan kerja, kewajiban atau tugas. Kinerja pegawai pada hakikatnya dalam rangka pelaksanaan tugas dan fungsi yang diberikan dengan menggunakan kemampuan dan potensi yang dimilikinya untuk mencapai tujuan organisasi yang telah ditetapkan. Oleh karena itu, iklim organisasi memiliki kontribusi yang cukup signifikan terhadap setiap individu di sebuah organisasi yang pada akhirnya berpengaruh terhadap kualitas kerja pegawai.

Dengan demikian berdasarkan analisis diatas, dinyatakan bahwa terdapat pengaruh langsung positif antara variabel iklim organisasi dengan variabel kinerja guru PAUD di Kota Depok dapat diterima.

\section{SIMPULAN}

Penelitian ini memaparkan adanya pengaruh antar variabel secara lebih spesifik, yaitu iklim organisasi berpengaruh langsung positif terhadap kinerja guru artinya iklim organisasi yang kondusif mengakibatkan peningkatan kinerja guru di Pendidikan Anak Usia Dini Kota Depok terutama di wilayah Kelurahan Gandul Kecamatan Cinere. Oleh karena itu, iklim organisasi disebuah lembaga dalam konteks penelitian ini adalah sekolah harus memiliki iklim yang kondusif agar pegawai (guru) dapat bekerja sesuai dengan tuntutan pekerjaannya. Dengan demikian, kinerja seseorang dipengaruhi oleh iklim organisasi yang kondusif. Oleh sebab itu, berdasarkan uraian hasil penelitian di atas, maka diajukan beberapa rekomendasi sebagai berikut, yaitu penelitian ini membuktikan adanya pengaruh iklim organisasi terhadap kinerja guru PAUD di Kota Depok sehingga iklim organisasi dalam konteks penelitian ini iklim lembaga PAUD harus dibuat kondusif agar para guru dapat mengajar dengan tenang dan untuk penelitian berikutnya mengenai kinerja, disarankan untuk mengukur kinerja seorang guru diperlukan penilaian kinerja dari orang lain, yaitu penilaian dari kepala sekolah, karena dalam penelitian ini, penilaian hanya dilakukan oleh guru itu sendiri, tidak dilakukan oleh kepala sekolah.

\section{UCAPAN TERIMAKASIH}

Penulis mengucapkan terima kasih kepada pembimbing yang sudah membantu peneliti menyempurnakan hasil penelitian ini serta ucapan terimakasih juga disampaikan kepada tim editor Jurnal Obsesi yang telah membantu penulis menerima dan mempublikasi artikel penelitian ini.

\section{DAFTAR PUSTAKA}

Aan Komariah dan Cepi Triatna, (2005). Visionary Leadership menuju Sekolah Efektif. Jakarta: Bumi Aksara

Asi, S. P. (2013). Pengaruh Iklim Organisasi dan Burnout terhadap Kinerja Perawat RSUD Dr. Doris Sylvanus Palangka Raya. Jurnal Aplikasi Manajemen, 11(3).

Gareth R, J., \& George, J. M. (2012). Contemporary Management. New York: Mc Graw Hill.

Idrus, M. (2006). Implikasi Iklim Organisasi terhadap Kepuasan Kerja dan Kualitas Kehidupan Kerja Karyawan. Jurnal Psikologi, 3(1). https:// doi.org/10.14710/jpu.3.1.94- 106

Jakaria, Y. (2014). Analisis Kelayakan dan Kesesuaian antara Latar Belakang Pendidikan Guru Sekolah Dasar dengan Mata Pelajaran yang Diampu. Jurnal Pendidikan Dan Kebudayaan, 20(4), 499. https:/ / doi.org/10.24832/jpnk.v20i4.162

Jones, N. A., H. Ross, T. Lynam, P. Perez, and A. Leitch. 2011. Mental models: an interdisciplinary synthesis of theory and methods. Ecology and Society 16(1):46. [online]

Keith, D., \& Newstrom, J. W. (2009). Perilaku dalam Organisasi. Jakarta: Erlangga.

Mullins, L. J. (2013). Management and Organizational Behavior. England: Financial Times.

Nugraeni, E. (2016). Penilaian Kinerja Guru dengan Strategi “Smart." Jakarta: Simposium GTK 
DOI: 10.31004/obsesi.v4i1.236

Kemendikbud.

Oebaidillah, Syarief. (2016). Kualitas Guru PAUD Harus Ditingkatkan. Jakarta: Media Indonesia.

Riduwan dan Engkos Achmad Kuncoro. (2013). Cara Menggunakan dan Memaknai Path Analysis (Analisis Jalur). Bandung: Alfabeta.

Robbiyah, R., Ekasari, D., \& Witarsa, R. (2018). Pengaruh Pola Asuh Ibu terhadap Kecerdasan Sosial Anak Usia Dini di TK Kenanga Kabupaten Bandung Barat. Jurnal Obsesi : Jurnal Pendidikan Anak Usia Dini, 2(1), 76-84. doi:http://dx.doi.org/10.31004/obsesi.v2i1.10

Surya, Y. (2017). Penggunaan Model Pembelajaran Pendidikan Karakter Abad 21 \pada Anak Usia Dini.Jurnal Obsesi : Jurnal Pendidikan Anak Usia Dini, 1(1), 52-61. doi:http:/ / dx.doi.org/10.31004/obsesi.v1i1.31

Triatna, Cepi. (2015). Perilaku Organisasi dalam Pendidikan. Bandung: PT. Remaja Rosdakarya.

Wardani, Listiana Kusuma. (2014). Pengaruh Kepemimpinan, Motivasi Kerja, dan Komitmen Organisasi terhadap Kepuasan Kerja dalam Meningkatkan Kinerja Guru SMP Negeri Kota Tegal. 1-14.

Wahyudi, Imam. (2012). Pengembangan Pendidikan Strategi Inovatif dan Kreatif dalam Mengelola Pendidikan Secara Komprehensif. Jakarta: Prestasi Pustaka Publisher.

Wirawan. (2009). Budaya dan Iklim Organisasi: Teori Aplikasi dan Penelitian. Jakarta: Salemba Empat. 